\title{
Comentários: O que é o Conhecimento em Marketing no Brasil, Afinal?
}

Sérgio C. Benício de Mello

Um trabalho realizado com o objetivo de verificar a situação e orientação da pesquisa científica da área de marketing no Brasil detectou que, entre os anos de 1990 e 2005, dos 527 artigos apresentados nos EnANPADs e no EMA, 407 adotaram uma abordagem positivista, 108 foram de cunho conceitual e 12 se enquadraram em uma abordagem interpretativista. O predomínio dos trabalhos positivistas retrata a orientação dada pelo marketing mainstream, que enfatiza a utilização e o desenvolvimento de medidas e modelos que possam auxiliar os gerentes no julgamento das atividades de marketing (cf. Day \& Montgomery, 1999). Esse resultado também foi observado por Kovacs et al. (2004, p. 13), que verificou que "a grande maioria dos trabalhos publicados na área de marketing do EnANPAD é de ordem quantitativa", o que nos sugere consonância com a orientação dominante neste campo de conhecimento. Estudo desenvolvido por Vieira et al. (2002, p. 2) encontrou resultados que demonstram que "a produção nacional reproduz as oscilações e os modismos de inspiração quase que exclusivamente norte-americana". Faria (2004, p. 2) corrobora a opinião dos autores acima, quando afirma que "a produção acadêmica em marketing no Brasil ainda é majoritariamente subordinada ao que é produzido nos EUA".

Tal posição ocupada pela academia brasileira de marketing, dentro de uma matriz colonialista, retrata uma experiência da dependência que, segundo Hall (2003), destrói as subjetividades, inferiorizando as manifestações locais na geração de um conhecimento construído com base em suas próprias necessidades. O pensamento hegemônico das elites especialistas identifica-se com os colonizadores e tenta reproduzir as idéias deles, opondo-se de modo preconceituoso à cultura e aos interesses - da sociedade em geral.

Martin-Barbero (2003) defende que, na dominação colonial, ocorre um processo de enculturação ${ }^{(1)}$, não por meio de simples repressão, mas pela produção de cultura: uma indústria de imagens e narrativas, que participa da construção da hegemonia, permitindo ao povo ter acesso à linguagem na qual ela se articula. Dessa forma, assinala-se o papel das idéias, e aí incluímos o conhecimento em 
marketing, como metanarrativa, na configuração e manutenção de padrões de desenvolvimento que impulsionam algumas regiões em detrimento de outras. Assim, a transposição dos modelos de análise, de conceitos, ou a importação de currículos escolares, além da supervalorização de publicações estrangeiras, ocorrem a despeito do conhecimento das necessidades específicas dos mercados locais.

O marketing norte-americano é o melhor representante do mainstream e apresenta a administração de marketing como o gerenciamento dos quatro P's (produto, promoção, preço e praça) (Bordern, 1984; Desphandé, 1999; Kotler, 2000; McCarthy, 2002), os quais se mantêm então como pilares centrais de sua ideologia. A sua associação máxima, a American Marketing Association, ou simplesmente AMA, define marketing como sendo "uma função organizacional e um conjunto de processos para criar, comunicar e entregar valor para os clientes e para gerenciar relacionamentos com o cliente de forma a beneficiar a organização e seus stakeholders" (acesso on-line, 2005).

É oportuno, no entanto, questionarmos se o conhecimento de marketing, gerado nas pesquisas realizadas pela nossa academia, é adequado e/ou reflete a realidade brasileira. Quando focalizamos a discussão da forma como o marketing mainstream vem construindo conhecimento, Brown (1993) elucida que os acadêmicos que seguem essa tradição entendem que a realidade existe; que ela pode ser compreendida, modelada e manipulada; que generalizações significativas podem ser realizadas; e, por último, que predições "exatas" podem ser feitas. Assim, aquilo que porventura seria essa realidade do que é marketing se assemelha em muito com aquele processo apregoado por Berger e Luckmann (2002) acerca do existir da institucionalização ${ }^{(2)} \mathrm{e}$ da vida cotidiana ${ }^{(3)}$.

A retórica desse marketing nos passa a impressão de que haveria uma unicidade no seu discurso, e que ele seria uma área de conhecimento próxima ao "caso normal"(4). Tratar-se-ia para aqueles que propagam essa "seita", bem como para os novos "fieis", de algo estável, cuja facticidade é evidente, já existente. Esse marketing se impõe à consciência dessas pessoas de maneira mais maciça, urgente e intensa do que as demais manifestações [universos simbólicos] de marketing. Isso ocorre devido a ser aquela realidade que possui maior poder (por conta da sua ampla divulgação e aceitação, conforme nos exibe o texto intitulado "pesquisa cientifica na área de marketing: uma revisão histórica", publicado nesta edição); logo sua ideologia é adotada como meio para "catequizar" aqueles que adentram nesse universo e são socializados por ele.

A socialização primária ${ }^{(5)}$ do marketing, isto é, se ele tiver uma, é a do 
mainstream. Isso acarreta impactos nas mediações simbólicas e nos mecanismos utilizados para a sedimentação, legitimação e, conseqüentemente, nos demais aparatos utilizados para realizar a socialização nesse universo. Nesse sentido, podemos falar que o estado de vigília de existir nessa realidade de marketing mainstream e de apreendê-la é considerado normal e evidente, porquanto seus fenômenos se acham previamente dispostos em padrões que parecem ser independentes da apreensão que tenhamos deles e que se impõem à nossa percepção.

Realmente fica um pouco difícil negá-la como a realidade, quando somos educados [socializados] por intermédio dela, assim como quando as grandes corporações aplicam essa visão de mundo de marketing com sucesso. Em outras palavras, somos embebidos nessa realidade, a ponto de não contemplarmos algo diferente além daquilo que preconizam os mainstreamers (e.g., Bordern, 1984; Desphandé, 1999; Kotler, 2000; McCarthy, 2002). Mas por que não procuramos nada diferente?

Por incrível que pareça, o marketing mainstream possui "todos" os conhecimentos para solucionar qualquer problema de troca; mesmo quando a situação é problemática, ou seja, quando seu fluxo é interrompido pelo aparecimento de um problema, essa realidade de marketing procura integrar o setor problemático dentro daquilo que já é não-problemático, como forma de manter a ordem da realidade (cf. Kuhn, 1970).

Além disso, como não podemos existir na vida cotidiana sem estar continuamente em interação e comunicação com os outros, são exatamente esses outros (particularmente os especialistas) que nos possibilitam "acreditar" que só existe o marketing mainstream. Eles nos ensinam, bem como reforçam e legitimam as normas, condutas, regras e tipificações dessa instituição, incorporando-as ao cotidiano, quando passam a ser "práticas" habituais e "necessárias".

Para diagnosticarmos ainda mais essa situação, ao adentrarmos nessa comunidade de vida (i.e., academia de marketing), desempenhamos, durante nosso processo de socialização nela, papéis de consumidores de sentido dessa e nessa instituição, como também a auxiliamos na produção de seus sentidos, ao praticarmos nossos atos. Tal reciprocidade entre os sujeitos interagentes desse mundo permite a manutenção e a perpetuação dessa comunidade como a realidade.

Para piorar o prognóstico, mesmo quando o marketing mainstream não adota "estratégias" de aniquilação ${ }^{(6)}$ dos universos simbólicos concorrentes (e.g., 
interpretativismo), esse marketing adota "estratégias" terapêuticas ${ }^{(7)}$ no ímpeto de realizar a fagocitose desses universos, de forma que sejam percebidos como "meios" válidos do mainstream para reforçar seus valores (supra-ordenados). Assim, o ecletismo do marketing fica comprometido, o que mantém a auto-evidência do mainstream.

Todavia tal tentativa tem sido um tanto quanto frustrada para não dizer inútil, pois nenhuma sociedade (e.g., academia de marketing), nem mesmo a mais primitiva, chegaria ao estágio de "caso normal", em que não haveria espaço para divergências quanto aos ditames da comunidade de vida; logo não poderia haver crises. Na verdade, essa busca total de consistência de valores, de almejada comunhão de sentidos pelo mainstream, não passa de utopia; haja vista que, se não houver crise, não refletimos sobre a ordem, nem sobre o sentido da vida, ou seja, não vislumbramos a relação entre nossas experiências dentro de determinada instituição, tampouco acerca da "certeza" desse mundo. Em outras palavras, sem a existência da crise não podemos perceber nossa identidade pessoal, assim como a identidade institucional. Dessa forma, a discrepância entre o ser e o deve ser, entre expectativas e realização prática de vida tem de existir para o ser da vida institucional.

Como as áreas de sentido são estratificadas e o pluralismo ${ }^{(8)}$ catalisado pela modernidade, é uma "constante", as tentativas de consistência, como aquela realizada, por exemplo, pelo artigo seminal de autoria de Day e Montgomery (1999), publicado pelo ícone do mainstream, o Journal of Marketing, em que os autores propõem solucionar (de forma infrutífera) a crise que reina no marketing, não passam de meras formas insuficientes de superar a crise de sentido no mainstream, porquanto não basta dar uma nova roupagem, nem abranger o escopo de atuação do marketing, se não há instituições "intermediárias" ${ }^{(9)}$ que permitam que as comunidades inseridas realizem a ponte entre os indivíduos (produtores e consumidores de sentido em marketing) e a instituição de marketing.

Diante do exposto, apesar do mainstream simular o ponto de "chegada-fim" almejado pelas instituições, ou seja, os valores (supra-ordenados), essa retórica não conseguirá por si própria - por meio do discurso da unicidade simbólica - dar conta da multiplicidade de universos simbólicos (e.g., realidade das pequenas empresas), conseqüentemente do pluralismo. Como a modernidade intensificou o pluralismo, logo a crise de sentido, o marketing mainstream deve permitir o emergir da relação dialética de perda de sentido, o que acarretará nova criação de sentido, um neo-new-novo-marketing. 
Assim, o marketing mainstream é direcionado e atende basicamente aos interesses de grandes corporações. E as pequenas organizações como ficam? Os textos do marketing mainstream não oferecem suporte a essas empresas que, segundo pesquisa do SEBRAE divulgada em 2005, correspondem a 99,2\% de todas as empresas brasileiras formais no ano de 2002. Sob a perspectiva do empreendedor, o marketing é experiência diária que envolve buscar boas idéias que funcionem para melhorar produtos e serviços, melhorar ou manter as habilidades e motivações dos funcionários, gerar mais negócios e criar marcas distintas e lucrativas no mercado.

Dessa forma, para entender as ações de marketing realizadas pelos empreendedores de pequenas empresas seria adequado utilizar pesquisas com perspectiva onto-epistemológica socioconstrucionista que ofereçam interpretações das pré-condições etnometodológicas que ocorrem neste determinado contexto (Hackley, 2001), isto porque o marketing é construído em cada contexto organizacional. Ele não é unificado. Pesquisas com este enfoque poderiam gerar idéias para os empreendedores de pequenos negócios quanto às ações de marketing mais indicadas para as suas necessidades.

Ainda assim, podemos perguntar-nos também: e quanto aos consumidores? O discurso deste marketing mainstream aponta a satisfação das necessidades e dos desejos dos consumidores como o seu maior objetivo, sendo a lucratividade das organizações uma conseqüência deste pressuposto. Mas, convenhamos, não é bem isso o que vemos. O marketing é realizado por pessoas e para pessoas; quando o quadro posto em suas pesquisas no Brasil aponta a utilização de metodologias de pesquisas que privilegiam a dualidade estímulo-resposta, elas perdem a oportunidade de destacar em suas reflexões o maior diferencial que o ser humano possui: o poder que ele tem de ser consciente, em face das situações a que está exposto.

Alinhamo-nos às idéias de Araújo (1999, p. 3) em seu ensaio sobre Schopenhauer. Ele enfatiza que "o desejo está por toda a parte. Ele é como a raiz e o princípio primeiro do mundo que extravasa do agir humano. Em todos os fenômenos da natureza, da vida dos astros ao instinto dos animais e mesmo no querer consciente dos homens, encontramos a manifestação desse desejo. Não somos tão livres quanto pensamos, pois tudo o que acontece, acontece segundo a necessidade. O corpo objetiva o desejo enquanto impulso, infinito, uno e irracional e independe de qualquer individuação. Todo ato real do desejo do sujeito é o movimento de seu corpo e o corpo é apenas esse desejo tornado visível, é o próprio desejo enquanto objeto da intuição. Assim, toda impressão exercida sobre o corpo afeta imediatamente o desejo, onde aparece, então, o 
prazer e a dor. O mundo, em sua totalidade, é uma manifestação de força irracional como desejo".

"Todo querer se origina da necessidade, portanto da carência e do sofrimento. A satisfação lhe põe um termo; mas para cada desejo satisfeito, dez permanecem irrealizados", assim pensava Arthur Schopenhauer (2005, Livro III §38). Os seres humanos são criaturas ativas que se encontram compelidos a amar, a odiar, ao desejo e à rejeição. Os homens possuem o conhecimento de que a natureza é irredutivelmente desse modo. Mesmo assim, parecem disso esquecer-se ao desenvolver um conceito que tem no seu cerne a satisfação da necessidade e do desejo do homem enquanto consumidor.

Deveríamos preocupar-nos em compreender o que realmente os consumidores valorizam nos produtos e nas marcas ofertadas aos mercados pelas organizações e não simplesmente em como "identificar" necessidades e desejos a serem satisfeitos e de que maneira. Precisamos entender como os produtos e as marcas se tornam parte de suas vidas. Afinal de contas, numa sociedade de consumo, que signos mais emblemáticos podemos ter? Mais uma vez abordagens socioconstrucionistas e também sociointeracionistas podem ajudar-nos nesta empreitada.

Tentativas teóricas foram elaboradas na literatura de marketing mediante tipologias como as seguintes: marketing de relacionamento (Christopher et al., 1999; Grönroos, 2004) e marketing de serviços (Lovelock, 1996; Palmer, 1996), para a compreensão do significado das ações que valorizam os momentos de interação. Entretanto a questão é esta: o tratamento dado pela academia brasileira é suficiente para o entendimento do marketing como fenômeno social constituído por ações cotidianas? Que impactos essas tipologias de marketing geram tanto para os produtores quanto para os consumidores?

A "orientação para o mercado" (Day, 2001), concretização dos atos das empresas e seus efeitos em seus mercados de atuação são obtidos de forma dinâmica e interativa nos momentos em que a organização está em contato com os seus diversos agentes: fornecedores, clientes externos e internos, parceiros, concorrentes, enfim. É no vivido, e não apenas por meio da projeção da criação de um novo produto ou de um novo plano de marketing, concebido por teorizações constitutivas de casos narrados por grandes empresas, como se baseia a maioria das construções do conhecimento em marketing no Brasil, que essa supracitada orientação se constitui.

Se a busca da compreensão dos fenômenos de marketing parece estar localizada 
na interação de produtor e consumidor e na geração do sentido que a relação proporciona para ambos, parece não caber aqui respostas determinísticas e generalistas, apenas apontamentos de caminhos que possam engendrar o utópico ponto de "chegada-fim".

Dessa forma, como o ser humano não nasce homem, ele se torna homem ao estar em sociedade, e que os processos de socialização são fundamentais na formação da identidade e dos selves (cf. Mead, 1934) e que a sociedade é a instituição formada por esses diversos homens, propomos a seguinte reflexão: que tipo de homem (cidadão) está sendo criado pela retórica do marketing tão impregnado no senso-comum?

A academia de marketing não estaria precisando de um olhar mais humanizado, abrangente e interdisciplinar para uma melhor compreensão do impacto que o pensamento e o discurso retórico do marketing estão gerando, tanto na ciência da administração quanto na sociedade como um todo?

Assim, faz-se necessário realizar um processo de descolonização da academia brasileira de marketing em face do pensamento hegemônico, de forma que os especialistas brasileiros possam construir "novos" saberes de marketing que atendam à realidade do mercado local. Isso pode ser realizado por meio do estimulo da pluralidade, abrindo nessa comunidade de vida espaços de discussão de conhecimento (i.e., áreas de sentido estratificadas) diferentes do pensamento dominante e construído com base em suas próprias necessidades.

Além disso, deveria haver por parte desses especialistas uma assimilação mais crítica dos modelos importados do pensamento referenciado acima, levando em consideração as idiossincrasias do Brasil, no ímpeto de utilizá-los de maneira mais consciente. De fato, por ser voltado para as grandes corporações, não se pode transpor literalmente os construtos desta realidade para aquela das pequenas empresas brasileiras sem os devidos cuidados, sob pena de ineficiência dessas modelagens.

Por fim, deveria haver investimentos nas instituições "intermediárias" como mediadoras da conscientização dos interagentes da comunidade de vida de marketing, a fim de descolonizá-los, amenizando assim a sua alienação, em face do pensamento hegemônico. Tal fato propiciará a emergência de "novos" saberes. Além disso, é por intermédio dessas instituições que haverá por parte da área de marketing a amenização da crise de sentido, mas não ainda a sua superação. 


\section{NotAs}

${ }^{1}$ A enculturação consiste no processo de dominação através da introdução e assimilação dos aspectos da cultura dominante, em detrimento da cultura dominada (cf. Martin-Barbero, 2003).

${ }^{2}$ A institucionalização é o processo de construir socialmente as instituições. As instituições são ordens sociais que possuem normas, padrões, tipificações, valores, regras e crenças que controlam o desempenho dos papéis daqueles que estão sob sua égide (Berger \& Luckmann, 2002).

${ }^{3}$ A vida cotidiana é considerada a realidade, porque é real, sua facticidade é evidente, não requerendo maior verificação que se estenda além de sua simples presença. O mundo da vida cotidiana é tomado como realidade certa, já existente. Apresenta-se como realidade interpretada pelos homens, sendo produto humano. Ela é subjetivamente dotada de sentido para eles na medida em que forma um mundo coerente; portanto origina-se do pensamento e na ação dos homens comuns (intersubjetividade). E por fim, dirige a conduta da vida diária (Schütz, 1967).

${ }^{4} \mathrm{O}$ "caso normal” significa pressupor uma situação que tenha alcançado alto grau de bem-estar, a ponto de não sofrer nenhuma ameaça direta de fora, e que possam ser negociados de modo bastante pacifico os diversos interesses dos grupos (Berger \& Luckmann, 2004).

${ }^{5}$ A socialização primária é a primeira socialização que o indivíduo experimenta na infância e em virtude da qual se torna membro da sociedade. É imediatamente evidente que a socialização primária tem em geral para o indivíduo o valor mais importante e que a estrutura básica de toda a socialização secundária deve assemelhar-se à da socialização primária (cf. Mead, 1934)

${ }^{6}$ A aniquilação usa um mecanismo semelhante ao da terapêutica para liquidar conceitualmente tudo o que está situado fora deste mesmo universo. É realizada com indivíduos ou grupos estranhos à sociedade em exame e por isso inelegíveis para a terapêutica. Consiste em expugar e eliminar qualquer individuo, grupo ou universo simbólico concorrente que ameace a existência de determinada ordem institucional (Berger \& Luckmann, 2002)

${ }^{7}$ A terapêutica acarreta a aplicação do mecanismo conceitual, a fim de assegurar que os discordantes atuais ou potenciais se conservem dentro das definições institucionalizadas da realidade. A conduta do dissidente desafia a realidade social como tal, pondo em questão seus procedimentos operatórios cognoscitivos admitidos como certos. A terapêutica ressocializa o transviado, reintroduzindo-o na realidade objetiva do universo simbólico da sociedade (Berger \& Luckmann, 2002)

${ }^{8} \mathrm{O}$ pluralismo leva a um enorme relativismo dos sistemas de valores e da interpretação. Os antigos sistemas de valores e de interpretação são "descanonizados". A "alienação" e a "anomia" dificultam as pessoas de encontrar um caminho no mundo moderno. Esse processo promove a difusão de crises subjetivas e intersubjetivas, desacreditando o "conhecimento" auto-evidente (cf. Durkheim, 1999).

${ }^{9}$ As instituições intermediárias são aquelas que permitem ao individuo colocar a serviços de vários setores da sociedade os valores de sua vida privada de modo a constituírem uma força que ajude a formar a sociedade como um todo. Elas realizam a ponte entre o individuo e os padrões de experiência e ação estabelecidos na sociedade. Assim, a pessoa colabora na produção e processamento do acervo social de sentido (Berger \& Luckmann, 2004). Por exemplo, essa instituição se faz existir na metafora das ágoras, representadas aqui pelas "verdadeiras" conferências cientificas, cujo debate ocorre na esfera pública e visa à produção de conhecimento e sentido para os "novos" saberes. 


\section{Referencias Bibliográficas}

American Marketing Association (2005). Dictionary of marketing terms. Recuperado em 15 outubro, 2005, de http://www.marketingpower.com/mgdictionary-view329.php?

Araújo, R. (1999).

Schopenhauer e o drama do mundo. Ferrea Vox - Revista de Filosofia e Cultura, Recuperado em $1^{\circ}$ novembro, 2005, de http:// geocities.yahoo.com.br/ferreavox/ shopenhauer.html.

Berger, P. L., \&

Luckmann, T. (2004).

Modernidade, pluralismo e crise de sentido: a orientação do homem moderno. Petrópolis: Vozes.

Berger, P. L., \&

Luckmann, T. (2002).

A construção social da realidade. (18a ed.). Petrópolis: Vozes.

Bordern, H. N. (1984).

The concept of the marketing mix. Journal of Advertising Research, 24(issue 4), 7-12.

Brown, S. (1993).

Postmodern marketing? European Journal of Marketing. 27(issue 4), 1934.

Christopher, M.,

Payne, A., \&

Peck, H. (1999).

Relationship marketing: strategy and implementation. London: Butterworth-Heineman.
Day, G. S. (2001).

A empresa orientada para o mercado: compreender, atrair e manter clientes valiosos. Porto Alegre: Bookman.

Day, G. S., \&

Montgomery, D. B. (1999).

Charting new directions for marketing. Journal of Marketing, 63(special issue), 3-13.

Desphandé, R. (1999).

Forseeing marketing. Journal of Marketing, 63(special issue), 164-167.

Durkheim, E. (1999).

Da divisão do trabalho social (2a ed.). São Paulo: Martins Fontes.

Faria, A. (2004).

Em busca de relevância no âmbito de estratégia de Marketing. Anais do Encontro Nacional dos Programas de Pós-Graduação em Administração, Curitiba, PR, 28.

Grönroos, C. (2004).

Marketing: gerenciamento e serviços (2a ed.). Rio de Janeiro: Elsevier.

Hall, S. (2003).

Da diáspora: identidade e mediações culturais. Belo Horizonte: UFMG.

Hackley, C. (2001).

Marketing and social construction: exploring the rhetorics of managed consumption. London: Routledge. 
Kotler, P. (2000).

Administração de marketing: a edição do novo milênio. (10a ed.). São Paulo: Pearson.

Kovacs, M. H.,

Leão, A. L. M. S. de,

Vieira, R.S. G.,

Barbosa, L., \&

Dias, C. M. de (2004).

Podemos confiar nos resultados de nossas pesquisas? Uma avaliação dos procedimentos metodológicos nos artigos de marketing do EnANPAD. Anais do Encontro de Marketing da ANPAD, Porto Alegre, RS, $1^{\circ}$.

Kuhn, T. S. (1970).

The structure of scientific revolutions (2nd ed.). Chicago: University of Chicago Press.

Lovelock, C. H. (1996),

Services Marketing (3rd ed.). New Jersey: Prentice Hall College Div

Martin-Barbero, J. (2003).

Dos meios às mediações: comunicação, cultura e hegemoni ( 2 a ed.). Rio de Janeiro: UFRJ.

McCarthy, E. J. (2002).

Basic marketing (14th ed.). Homewood, Ill.: Richard D. Irwin.
Mead, G. H. (1934).

Mind, self, and society from the perspective of a social behaviorist. Chicago: Edited by Charles W. Morris. University of Chicago.

Palmer, A. (1996).

Relationship marketing: a universal paradigm or management fad? The Learning Organization, 3(3), 18-25.

Schopenhauer, A. (2005).

$O$ mundo como vontade e como representação. São Paulo: UNESP.

Schütz, A. (1967).

Phenomenology of the social world. Edmonton: Northwestern University Press.

Serviço Brasileiro de Apoio às Micro e Pequenas Empresas (2005).

Boletim Estatístico de micro e pequenas empresas. $1^{\circ}$ semestre, 2005. Recuperado em 30 outubro, 2005, http://www.sebrae.com.br/br/ mpe_numeros/

Vieira, R. S. G.,

Dias, C. M. de,

Filho, J. R., \&

Neto, M. A. dos (2002).

O conhecimento de marketing sob os olhos da teoria crítica. Anais do Encontro Nacional dos Programas de Pós-Graduação em Administração, Salvador, BA, 26. 